\title{
Knowledge and Awareness Regarding Mental Health and Barriers to Seeking Psychiatric Consultation in Saudi Arabia
}

\author{
Mahmoud Abdulrahman Mahmoud \\ Department of Public Health, College of Medicine, IMAM Mohammad Ibn Saud Islamic University, Riyadh, \\ Riyadh Province, Saudi Arabia; communitydr@hotmail.com
}

\begin{abstract}
The Middle Eastern region, in general and Saudi Arabia, in specific, suffers from a large burden of mental illness. People's positive attitudes and correct perceptions towards mental illness and their willingness to seek help when needed can help in reducing such burden. To determine the knowledge, attitudes and perceptions of the Saudi population toward mental illness and health services and to understand the barriers that affect the people's willingness to seek psychiatric help when needed. A convenient sample of Saudi population of either sex was included in the study. A structured questionnaire was used to assess knowledge, attitudes and perceptions on mental health and the willingness to seek psychiatric help through multi-approach methods. Logistic regression was used to determine factors that were associated with not willing to seek psychiatric help, adjusting for other factors in the model. A total of 5644 participants (49.5\% males) participated. About $87 \%$ were unaware about psychiatric services available in the kingdom, $85 \%$ reported that social factors were responsible for mental illnesses, about a quarter of them reported that they wouldn't seek psychiatric help when needed and about half felt ashamed about it. Male gender, $>20$ years age group, not knowing whether a relative is suffering from mental illness and not knowing about the services provided by psychiatric health services in the kingdom were significantly associated with not willing to seek psychiatrist consultation when needed. A number of gaps were identified in the people's knowledge about mental illness. Anti-stigma campaigns and evidence-based mental health educational programs should be implemented to enable people to reduce stigma and seek early mental health care.
\end{abstract}

Keywords: Awareness, Barriers, Educational Programs, Knowledge, Mental Health, Saudi Arabia, Treatment-Seeking

\section{Introduction}

Mental health disorders, according to the World Health Organization (WHO), are one of the leading causes of disability worldwide; three out of ten leading causes of disability in people aged 15-44 years were mental disorders ${ }^{1}$. The mental health action plan for 2013$2020^{2}$, published by the WHO, highlighted the need for a collective evidence based effort to improve mental health. Mental illnesses have been known to account for
$25 \%$ of disabilities in some developed countries ${ }^{3-5}$. It is also considered to be the leading cause of disability in the rest of the world. The cost associated with mental illness is very high-in the US, the annual cost was estimated to be USD 190 billion and the global cost was estimated to be USD 2.5 trillion and it was estimated to reach USD 6 trillion by $2030^{5,6}$.

Epidemiologic studies have demonstrated a wide variation in the prevalence of common mental disorders across countries. Mental disorders contribute a significant

${ }^{*}$ Author for correspondence 
proportion (14\%) to the global burden of disease $\mathrm{F}^{7}$ Participants often present to their family physician as their first contact with health services. Yet, symptoms are commonly undetected. Although potentially treatable, lack of early detection and the subsequent non-treatment result in substantial morbidity and contribute to the higher social burden of disease. Internationally, the public health burden of anxiety and depression are well recognized ${ }^{8}$.

The Eastern Mediterranean Region has a population of about 580 million people. Countries in the EMR vary significantly in terms of their gross domestic product, socio-demographic profiles, health indicators and health system capacities. Mental disorders are common in the EMR. The prevalence of mental illness in the region has been reported to vary from $16 \%$ to $36 \%{ }^{9-11}$. In 2015 , mental disorders contributed to $5 \%$ of the total disease burden in the EMR. Among the high-income countries in the EMR, mental disorders contributed to 2519 DALYS/100,000. Mental disorders rank as the ninth leading cause of disease burden in the EMR and the burden increased 11\% from 1990 to $2013^{12,13}$. Depression and anxiety disorders are the most frequent mental disorders, and rates in women are up to double those in men $^{14}$.

In accordance with the objectives of the national mental health program $^{15}$ to encourage community participation in the development of mental health care services, community members should be first assessed for their perception and attitude towards persons with mental illness and mental health services. Appropriate interventions could then be designed and implemented to help achieving this objective ${ }^{16}$. Hence, the current study aimed to determine the knowledge, attitudes and perceptions of the Saudi population toward mental illness and health services and to understand the barriers that affect the people's willingness to seek psychiatric help when needed.

\section{Methodology}

This was a cross-sectional study conducted in AprilMay of 2016. The study was conducted through a direct interview, phone interviews and online surveys through social media. All adult persons of either sex was eligible for inclusion in the study. For an assumed proportion (of those who will not consult a psychiatrist when needed) of $50 \%$, a precision of $1.5 \%$, an alpha level of $5 \%$ and a non-response rate of $25 \%$, the calculated sample size was
5692. The data collection was continued till the required sample size was achieved. The questionnaire developed by the authors contained sections on socio-demographic details and knowledge and perceptions about mental illness. A short description of the study objectives and an oral consent was presented before the participants could begin to answer the questions.

Descriptive statistics were presented as frequencies and percentages. Proportions of various explanatory variables were compared with the willingness to seek psychiatric consultation when needed by means of Chi square test. Multiple logistic regression was then performed to identify factors that were significantly associated with willingness to seek psychiatric consultation, after adjusting for other factors in the model. The decision to include variables in the model was based on statistical significance found in the bivariate analysis and relevance of the variable to the model building. All analyses were carried out in SPSS v.20. A $p$ value of $<0.05$ was considered to be statistically significant. The institute review board of the study hospital approved the research.

\section{Results}

A total of 5644 individuals were included in the analysis, after removing forms with major errors and those which were grossly incomplete. Gender distribution of the respondents was nearly equal. Majority (40\%) of the individuals were $>20$ years old, followed by 21-25year olds $(35 \%)$. More than three-quarters $(78 \%)$ of the respondents were currently single, while $21 \%$ were currently married. About two-thirds were students, while $22 \%$ were employed, $11 \%$ were unemployed and about two-thirds were educated upto graduate level and a similar percentage self-rated their economic status to be average. (Table 1).

When asked if any of their relatives suffered from any mental illness, about $36 \%$ said that at least one relative had a mental illness and about $64 \%$ said that they didn't know. A majority of the respondents said that family bonding was an important factor in preventing mental illness and about $85 \%$ reported that social factors were the main reasons for mental illness, followed by economic factors (24\%), environmental factors (23\%) and educational factors (19\%). A large majority $(87 \%)$ were unaware of the services provided by mental health facilities in the kingdom (which consist of 23 special psychiatric hospitals including 3 Amal hospitals and 90 mental health clinics in the general hospitals run by 
Table 1. Socio-demographic characteristics and knowledge and attitudes regarding mental illness among the study participants

\begin{tabular}{|c|c|c|}
\hline & No. & $\%$ \\
\hline \multicolumn{3}{|l|}{ Gender } \\
\hline Male & 2796 & 49.5 \\
\hline Female & 2848 & 50.5 \\
\hline \multicolumn{3}{|l|}{ Age (years) } \\
\hline$>20$ & 2272 & 40.3 \\
\hline $21-25$ & 1961 & 34.7 \\
\hline $26-35$ & 847 & 15.0 \\
\hline$>=36$ & 564 & 10.0 \\
\hline \multicolumn{3}{|l|}{ Marital status } \\
\hline Single & 4401 & 78.0 \\
\hline Married & 1182 & 20.9 \\
\hline Divorced & 61 & 1.1 \\
\hline \multicolumn{3}{|l|}{ Employment status } \\
\hline Employed & 1258 & 22.3 \\
\hline Unemployed & 624 & 11.1 \\
\hline Student & 3762 & 66.7 \\
\hline \multicolumn{3}{|l|}{ Educational level } \\
\hline Graduate & 3509 & 62.2 \\
\hline Diploma & 137 & 2.4 \\
\hline Less than diploma & 1991 & 35.3 \\
\hline \multicolumn{3}{|l|}{ Economic status } \\
\hline Excellent & 1583 & 28.0 \\
\hline Average & 3714 & 65.8 \\
\hline Weak & 347 & 6.1 \\
\hline \multicolumn{3}{|c|}{ Relative suffering from mental illness } \\
\hline None & 7 & 0.1 \\
\hline One & 1077 & 19.1 \\
\hline More than one & 938 & 16.6 \\
\hline Don't know & 3622 & 64.2 \\
\hline \multicolumn{3}{|c|}{$\begin{array}{l}\text { Perceived preventive measures for } \\
\text { mental illness }\end{array}$} \\
\hline Family bonding & 3405 & 60.3 \\
\hline Psychological counselling & 995 & 17.6 \\
\hline Exercise & 782 & 13.9 \\
\hline Professional comfort & 462 & 8.2 \\
\hline \multicolumn{3}{|c|}{$\begin{array}{l}\text { Know about services provided } \\
\text { by mental health facilities in the } \\
\text { kingdom }\end{array}$} \\
\hline Yes & 718 & 12.7 \\
\hline No & 4926 & 87.3 \\
\hline
\end{tabular}

\begin{tabular}{|l|l|l|}
\hline $\begin{array}{l}\text { If and when you feel the need, } \\
\text { would you be willing to consult a } \\
\text { psychiatrist }\end{array}$ & & \\
\hline Yes & 1424 & 25.2 \\
\hline No & 4218 & 74.8 \\
\hline $\begin{array}{l}\text { Feel ashamed when visiting a } \\
\text { psychiatrist }\end{array}$ & & \\
\hline Yes & 630 & 14.8 \\
\hline Slightly & 1339 & 31.4 \\
\hline No & 2296 & 53.8 \\
\hline $\begin{array}{l}\text { Perceived reasons for mental illness } \\
\text { (multiple response) }\end{array}$ & & \\
\hline Social factors & 4794 & 84.9 \\
\hline Economic factors & 1325 & 23.5 \\
\hline Environmental factors & 1294 & 22.9 \\
\hline Educational factors & 1085 & 19.2 \\
\hline Biological or genetic factors & 92 & 1.6 \\
\hline Family factors & 67 & 1.2 \\
\hline Religious factors & 80 & 1.4 \\
\hline Drugs & 54 & 1.0 \\
\hline Other factors & 76 & 1.3 \\
\hline
\end{tabular}

the Ministry of Health all over the kingdom). About three quarters of the participants reported that they were willing to consult a psychiatrist if the need arises and about half of the respondents said that they would feel ashamed to meet a psychiatrist, which signifies an element of stigma attached to mental illness (Table 1). The most common perceived mental illness in the society was depression (44\%), followed by obsessive disorders (19\%), anxiety (17\%) and others (20\%) (Figure 1).

In bivariate analysis, we found that male gender, younger age, single status, being a student, not knowing whether a relative is suffering from mental illness and not knowing about the mental health services provided in the kingdom were significantly associated with not willing to consult a psychiatrist when needed. But educational level, economic status and feeling ashamed to meet a psychiatrist were not statistically significant (Table 2). However, in the multiple logistic regression, male gender, $>20$ age group, not knowing whether a relative is suffering from mental illness and not knowing about the mental health services in the kingdom were significantly associated with not willing to seek psychiatrist consultation. In this model, marital and employment statuses were not found significant. The model was statistically significant 
Table 2. Barriers of willingness to consult a psychiatrist when the need arises among the study participants - bivariate analysis

\begin{tabular}{|c|c|c|c|c|c|}
\hline & \multicolumn{4}{|c|}{ Willingness to consult a psychiatrist } & \multirow[t]{3}{*}{$P$ value } \\
\hline & \multicolumn{2}{|c|}{ Yes } & \multicolumn{2}{|c|}{ No } & \\
\hline & No. & $\%$ & No. & $\%$ & \\
\hline \multicolumn{6}{|l|}{ Gender } \\
\hline Male & 552 & 19.8 & 2242 & 80.2 & $<0.001$ \\
\hline Female & 872 & 30.6 & 1976 & 69.4 & \\
\hline \multicolumn{6}{|l|}{ Age (years) } \\
\hline$>20$ & 508 & 22.4 & 1764 & 77.6 & $<0.001$ \\
\hline $21-25$ & 514 & 26.2 & 1445 & 73.8 & \\
\hline $26-35$ & 222 & 26.2 & 625 & 73.8 & \\
\hline$>=36$ & 180 & 31.9 & 384 & 68.1 & \\
\hline \multicolumn{6}{|l|}{ Marital status } \\
\hline Single & 1054 & 24.0 & 3345 & 76.0 & $<0.001$ \\
\hline Married & 349 & 29.5 & 833 & 70.5 & \\
\hline Divorced & 21 & 34.4 & 40 & 65.6 & \\
\hline \multicolumn{6}{|l|}{ Employment status } \\
\hline Employed & 333 & 26.5 & 923 & 73.5 & 0.003 \\
\hline Unemployed & 187 & 30.0 & 437 & 70.0 & \\
\hline Student & 904 & 24.0 & 2858 & 76.0 & \\
\hline \multicolumn{6}{|l|}{ Educational level } \\
\hline Graduate & 914 & 26.1 & 2594 & 73.9 & 0.13 \\
\hline Diploma & 29 & 21.2 & 108 & 78.8 & \\
\hline Less than diploma & 478 & 24.0 & 1512 & 76.0 & \\
\hline \multicolumn{6}{|l|}{ Economic status } \\
\hline Excellent & 372 & 23.5 & 1211 & 76.5 & 0.15 \\
\hline Average & 965 & 26.0 & 2747 & 74.0 & \\
\hline Weak & 87 & 25.1 & 260 & 74.9 & \\
\hline \multicolumn{6}{|c|}{ Relative suffering from mental illness } \\
\hline None & 1 & 16.7 & 5 & 83.3 & $<0.001$ \\
\hline One & 316 & 29.4 & 760 & 70.6 & \\
\hline More than one & 295 & 31.4 & 643 & 68.6 & \\
\hline Don't know & 812 & 22.4 & 2810 & 77.6 & \\
\hline \multicolumn{6}{|c|}{$\begin{array}{l}\text { Know about services provided by mental health } \\
\text { facilities in the kingdom }\end{array}$} \\
\hline Yes & 279 & 38.9 & 438 & 61.1 & $<0.001$ \\
\hline No & 1145 & 23.2 & 3780 & 76.8 & \\
\hline \multicolumn{6}{|c|}{ Feel ashamed when visiting a psychiatrist } \\
\hline Yes & 679 & 34.5 & 1289 & 65.5 & 0.10 \\
\hline No & 738 & 32.2 & 1557 & 67.8 & \\
\hline
\end{tabular}


Table 3. Barriers of willingness to consult a psychiatrist when the need arises among the study participants multiple logistic regression

\begin{tabular}{|c|c|c|}
\hline & $\begin{array}{l}\text { Adjusted Odds } \\
\text { Ratio (95\% CI) }\end{array}$ & $P$ value \\
\hline \multicolumn{3}{|l|}{ Gender } \\
\hline Male & 1 & \\
\hline Female & $0.51(0.44,0.58)$ & $<0.001$ \\
\hline Age (years) & & 0.007 \\
\hline$>20$ & 1 & \\
\hline $21-25$ & $0.76(0.65,0.89)$ & 0.001 \\
\hline $26-35$ & $0.80(0.61,1.06)$ & 0.12 \\
\hline$>=36$ & $0.72(0.51,1.01)$ & 0.05 \\
\hline Marital status & & 0.76 \\
\hline Single & 1 & \\
\hline Married & $0.92(0.73,1.14)$ & 0.45 \\
\hline Divorced & $0.95(0.54,1.66)$ & 0.86 \\
\hline Employment status & & 0.67 \\
\hline Graduate & 1 & \\
\hline Diploma & $1.09(0.87,1.38)$ & 0.43 \\
\hline Less than diploma & $1.09(0.86,1.38)$ & 0.46 \\
\hline $\begin{array}{l}\text { Relative suffering from } \\
\text { mental illness }\end{array}$ & & $<0.001$ \\
\hline One or less & 1 & \\
\hline More than one & $0.91(0.75,1.11)$ & 0.38 \\
\hline Don't know & $1.33(1.14,1.56)$ & $<0.001$ \\
\hline $\begin{array}{l}\text { Doesn't know about services } \\
\text { provided by mental health } \\
\text { facilities in the kingdom }\end{array}$ & $1.99(1.68,2.35)$ & $<0.001$ \\
\hline
\end{tabular}

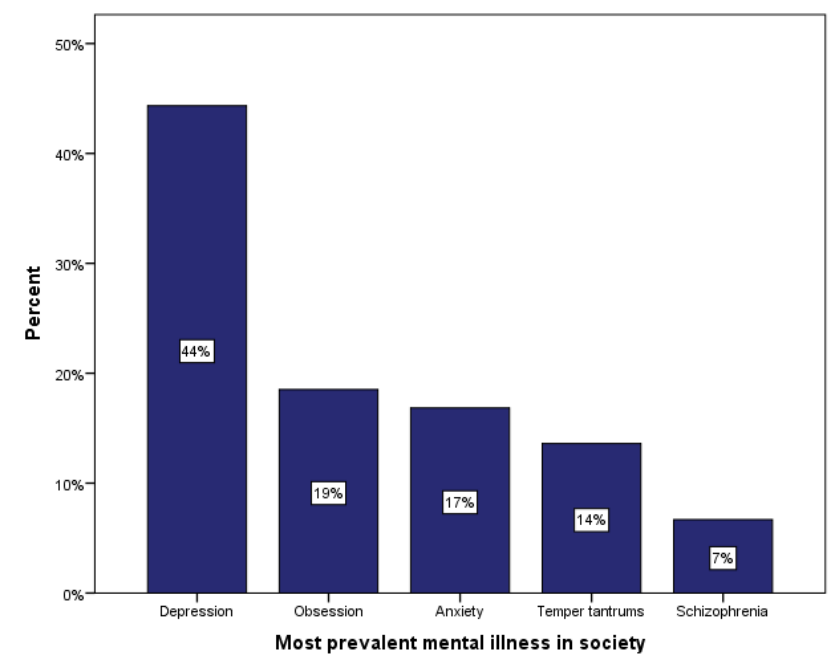

Figure 1. Common mental illnesses in the society as percieved by the study participants. (omnibus tests for model coefficients $\mathrm{p}<0.001$ ) and had a classification accuracy of $75 \%$, (Table 3 ).

\section{Discussion}

This cross-sectional study has explored the knowledge, attitude and perceptions of a sample of Saudi population regarding mental illness. It revealed that a large proportion were unaware of the health services available for mental illness, a quarter of them were unwilling to consult a psychiatrist if needed and nearly half were ashamed of meeting a psychiatrist, which denotes the widely prevalent stigma associated with mental illness in Saudi society. Also, the study demonstrated that factors such as gender, age, awareness of mental illness in family members and knowledge of available health services were significant in determining the willingness to seek psychiatric help, if and when needed.

The association between gender and the willingness to going to a psychiatrist was reported in a study conducted by Matheson et al., they showed that women with chronic physical illnesses were $10 \%$ more likely to seek support for mental health issues than men with similar illnesses. Also, women used medical services for mental health treatment earlier than men ${ }^{17}$. This may be because women feel more comfortable seeking mental health support or that symptoms are worse among them. Similar to our finding that older persons were more willing to seek psychiatric help, a study from Ethiopia ${ }^{18}$ showed that individuals aged 31-40 were about 10 times more likely to seek treatment than subjects under 20 years, which may be explained by the fact that older adults tend to have more knowledge about mental illness. However, a survey conducted in Singapore, reported that younger age was significantly associated with willingness to seek professional help ${ }^{19}$. There is still no conclusive evidence on the association between age and seeking psychological help. Some studies ${ }^{20-22}$ report that older adults have a negative attitude towards seeking help and some others ${ }^{23}$ have shown the opposite relationship. There is a need to further explore the role of age which may depend largely on knowledge and cultural contexts.

Marital status was significantly associated only in bivariate analysis in our study; single people wereless willing to seek help. This was similar to the findings of a study from Europe, which showed that people living together had a significantly higher score on the 'Total Attitude toward Treatment' scale in comparison to people living alone $\mathrm{e}^{24}$. 
This is troublesome because people who are living alone may be at higher risk of mental illness. Although we did not find any association between employment status and economic level and willingness to go to a psychiatrist, a study by Buffel et al., reported a significant association ${ }^{25}$, Unemployed persons may be pessimistic about their prospects and the employed may perceive greater job insecurity, which are risk factors for worse mental health.

On the effect of knowledge regarding the services available for mental illness, we found that those who had a better knowledge were also more likely to show willingness to seek psychiatric help. This relationship is straight forward in that people who have more knowledge about mental illness and keep themselves informed of the services available are more likely to harbor less stigma and would be more open to suggestions of take psychiatric help, when the need arises. Stigma is considered a major barrier to seek psychiatric treatment as many studies have reported ${ }^{26-29}$. We did not find an association between feeling shame and willingness to seek treatment, but a large proportion of respondent said that they indeed felt shameful about visiting a psychiatrist. A study ${ }^{30}$ conducted among parents of children with mental illness in the United Arab Emirates, reported that a significant proportion of the respondents showed reluctance to acknowledge that a member of their family had a mental illness and only $38 \%$ said that they would seek psychiatric help for a family member, including their children. Stigma has a major role to play in modifying the attitudes and behaviors of the population with regard to perceiving mental illness and treatment seeking decisions ${ }^{31}$. The stigma associated with mental illness prevents many mentally ill people and their caregivers from seeking adequate treatment. People may refuse to seek help from mental health professionals for fear of social reaction and may try to hide the illness, which lead to underestimation of the problem ${ }^{32}$.

\section{Limitations}

This study has been conducted with a large sample size and explored the important factors in reducing mental health burden. But there are some limitations that have to be taken into account. Since this was a cross-sectional study, cause-effect relationships between the factors found to be significantly associated with willingness to seek psychiatric help could not be conclusively established.
Future studies can be designed as a cohort to study these factors in a more valid manner. The convenient sampling methodology reduces the generalizability of the study findings but the huge sample is less likely to produce markedly variable results. But considering the social and cultural uniqueness of the Saudi society which limit random sampling in a community based setting, this study would serve as a usual first step. Factors other than those that have been considered here, such as religious beliefs $^{33}$, are also important and these factors should be explored in future studies.

\section{Conclusions and Recommendations}

Knowledge regarding available mental health services was poor in the Saudi population - significant proportion of the participants were hesitant to seek psychiatric help when needed and many harbored stigma towards mental illness. These and other factors were found to influence their willingness to seek help when needed.

In order to overcome the several gaps identified in this study, a complete overhaul of the national mental health program is required. There is a need to increase public awareness on the facts regarding mental health and the various services available through the health system. In addition to this, anti-stigma campaigns aiming to develop a healthy attitude to mental illness and evidence-based mental health educational programs insisting the importance of early treatment seeking and family participation in caring for the mental ill need to be implemented. Programs to enable people to seek early and sustained care will go a long way in reducing the burden of mental illness in Saudi Arabia.

\section{Funding}

None.

\section{Conflicts of Interest}

None declared.

\section{References}

1. Murray CJL, Lopez A. World Health Report 2002: Reducing Risks, Promoting Healthy Life. Geneva: WHO; 2002. 
2. World Health Organization. Mental health action plan 2013-2020. Geneva: WHO; 2013. http://www.who.int/ mental_health/publications/action_plan/en/

3. World Health Organization. Mental Health Atlas 2011. Geneva: WHO; 2011 p. 82.

4. World Health Organization. WHO Mental Health Gap Action Programme (mhGAP). Geneva: WHO; 2013.

5. National Alliance on Mental Illness. Mental Health 2013: An Important Public Health Issue. Arlington, VA: National Alliance on Mental Illness; 2013. http://www.namigc.org/ wp-content/uploads/2013/01/MentalIllnessFactSheetJuly-2013.pdf

6. Duckworth K. Mental illness facts and numbers. Arlington, VA: National Alliance on Mental Illness; 2013.

7. Prince M, Patel V, Saxena S, Maj M, Maselko J, Phillips $\mathrm{MR}$, et al. No health without mental health. Lancet Lond Engl. 2007 Sep; 370(9590):859-77. https://doi.org/10.1016/ S0140-6736(07)61238-0

8. Almutairi AF. Mental illness in Saudi Arabia: An overview. Psychol Res Behav Manag. 2015 Jan; 8:47-9. PMid: 25674019 PMCid: PMC4321637. https://doi.org/10.2147/ PRBM.S79268

9. Scholte WF, Olff M, Ventevogel P, de Vries GJ, Jansveld E, Cardozo BL, et al. Mental health symptoms following war and repression in eastern Afghanistan. JAMA. 2004 Aug; 292(5):585-93. PMid: 15292084. https://doi.org/10.1001/ jama.292.5.585

10. Noorbala AA, Bagheri Yazdi SA, Yasamy MT, Mohammad K. Mental health survey of the adult population in Iran. Br J Psychiatry. 2004 Jan; 184(1):70-3. PMid: 14702230. https:// doi.org/10.1192/bjp.184.1.70

11. Abou-Saleh MT, Ghubash R, Daradkeh TK. Al A in community psychiatric survey. I. Prevalence and sociodemographic correlates. Soc Psychiatry Psychiatr Epidemiol. 2001 Mar; 36(1):20-8. PMid: 11320804. https:// doi.org/10.1007/s001270050286

12. Charara R, Forouzanfar M, Naghavi M, Moradi-Lakeh M, Afshin A, Vos T, et al. The burden of mental disorders in the Eastern Mediterranean Region, 1990-2013. PloS One. 2017; 12(1):e0169575. PMid: 28095477 PMCid: PMC5240956. https://doi.org/10.1371/journal.pone.0169575

13. GBD 2015 Eastern Mediterranean Region Mental Health Collaborators, Mokdad AH. The burden of mental disorders in the Eastern Mediterranean region, 1990-2015: Findings from the global burden of disease 2015 study. Int J Public Health. 2018 May; 63 (Suppl 1):25-37. PMid: 28776247.

14. Abdel Wahed WY, Hassan SK. Prevalence and associated factors of stress, anxiety and depression among medical Fayoum University students. Alex J Med. 2017 Mar; 53(1):77-84. https://doi.org/10.1016/j.ajme.2016.01.005
15. Al-Habeeb AA, Qureshi NA. Mental and social health atlas I in Saudi Arabia: 2007-08. East Mediterr Health J. 2010 May; 16(5):570-7. PMid: 20799560. https://doi. org/10.26719/2010.16.5.570

16. Bener A, Abou-Saleh MT, Dafeeah EE, Bhugra D. The prevalence and burden of psychiatric disorders in primary health care visits in Qatar: Too Little Time. J Fam Med Prim Care. 2015 Jan-Mar; 4(1):89-95. PMid: 25810996 PMCid: PMC4367013. https://doi.org/10.4103/2249-4863.152262

17. Matheson FI, Smith KLW, Fazli GS, Moineddin R, Dunn JR, Glazier RH. Physical health and gender as risk factors for usage of services for mental illness. J Epidemiol Community Health. 2014 Sep; 68(10):971-8. PMid: 24970764 PMCid: PMC4174114. https://doi.org/10.1136/ jech-2014-203844

18. Girma E, Tesfaye M. Patterns of treatment seeking behavior for mental illnesses in Southwest Ethiopia: A hospital based study. BMC Psychiatry. 2011 Aug; 11:138. PMid: 21859455 PMCid: PMC3170592. https://doi.org/10.1186/1471244X-11-138

19. Picco L, Abdin E, Chong SA, Pang S, Shafie S, Chua BY, et al. Attitudes toward seeking professional psychological help: Factor structure and socio-demographic predictors. Front Psychol. 2016 Apr; 7:547. PMid: 27199794 PMCid: PMC4842935. https://doi.org/10.3389/fpsyg.2016.00547

20. Estes C. Mental health services for the elderly: Key policy elements. Gatz $M$, editor. Emerging Issues in Mental Health and Aging. Washington, DC: American Psychological Association; 1995. p. 303-28. https://doi. org/10.1037/10179-012

21. Segal DL, Coolidge FL, Mincic MS, O’Riley A. Beliefs about mental illness and willingness to seek help: A cross-sectional study. Aging Ment Health. 2005 Jul; 9(4):363-7. PMid: 16019293 https://doi.org/10.1080/13607860500131047

22. Hatfield A. Barriers to serving older adults with a psychiatric disability. Psychiatr Rehabil J. 1999 Dec; 22(3):270-6. https://doi.org/10.1037/h0095234

23. Robb C, Haley WE, Becker MA, Polivka LA, Chwa H-J. Attitudes towards mental health care in younger and older adults: Similarities and differences. Aging Ment Health. 2003 Mar; 7(2):142-52. PMid: 12745392. https://doi.org/1 $0.1080 / 1360786031000072321$

24. Coppens E, Van Audenhove C, Scheerder G, Arensman E, Coffey C, Costa S, et al. Public attitudes toward depression and help-seeking in four European countries baseline survey prior to the OSPI-Europe intervention. J Affect Disord. 2013 Sep; 150(2):320-9. PMid: 23706876. https://doi.org/10.1016/j.jad.2013.04.013

25. Buffel V, van de Straat V, Bracke P. Employment status and mental health care use in times of economic contraction: a repeated cross-sectional study in Europe, using a three- 
level model. Int J Equity Health. 2015 Mar; 14:29. PMid: 25889356 PMCid: PMC4367872. https://doi.org/10.1186/ s12939-015-0153-3

26. Kulesza M, Pedersen E, Corrigan P, Marshall G. Helpseeking stigma and mental health treatment seeking among young adult veterans. Mil Behav Health. 2015; 3(4):230-9. PMid: 26664795 PMCid: PMC4672863. https://doi.org/10. 1080/21635781.2015.1055866

27. Conner KO, Copeland VC, Grote NK, Koeske G, Rosen D, Reynolds CF, et al. Mental health treatment seeking among older adults with depression: The impact of stigma and race. Am J Geriatr Psychiatry Off J Am Assoc Geriatr Psychiatry. 2010 Jun; 18(6):531-43. PMid: 20220602 PMCid: PMC2875324. https://doi.org/10.1097/ JGP.0b013e3181cc0366

28. Vidourek RA, King KA, Nabors LA, Merianos AL. Students' benefits and barriers to mental health help-seeking. Health Psychol Behav Med. 2014 Jan; 2(1):1009-22. PMid: 25750831 PMCid: PMC4346065. https://doi.org/10.1080/ 21642850.2014.963586
29. Czyz EK, Horwitz AG, Eisenberg D, Kramer A, King CA. Self-reported barriers to professional help seeking among college students at elevated risk for suicide. J Am Coll Health J ACH. 2013 Oct; 61(7):398-406. PMid: 24010494 PMCid: PMC3788673. https://doi.org/10.1080/07448481.2 013.820731

30. Eapen V, Ghubash R. Help-seeking for mental health problems of children: Preferences and attitudes in the United Arab Emirates. Psychol Rep. 2004 Apr; 94(2):663-7. PMid: 15154199. https://doi.org/10.2466/pr0.94.2.663-667

31. Sewilam AM, Watson AMM, Kassem AM, Clifton S, McDonald MC, Lipski R, et al. Roadmap to reduce the stigma of mental illness in the Middle East. Int J Soc Psychiatry. 2015 Mar; 61(2):111-20. PMid: 24957595 PMCid: PMC4852850. https://doi.org/10.1177/0020764014537234

32. Dawood E, Modayfer O. Public attitude towards mental illness and mental health services in Riyadh, Saudi Arabia. Res Humanit Soc Sci. 2016; 6(24):63-75.

33. Ciftci AJ. Mental health stigma in the Muslim Community. J Muslim Ment Health. 2012 Apr; 7(1):17-32. 